\title{
Fluctuation in physical symptoms, coping, and mood in patients following hematopoietic stem cell transplantation: assessing mediation effects using a daily diary approach
}

\author{
Aleksandra Kroemeke ${ }^{1}$ (D) Zuzanna Kwissa-Gajewska ${ }^{1}$ - Małgorzata Sobczyk- \\ Kruszelnicka ${ }^{2}$
}

Received: February 6, 2018/Accepted: August 29, 2018/Published online: September 3, 2018

(C) The Author(s) 2018

\begin{abstract}
This study examines the indirect effect between parallel fluctuation in daily physical symptoms, symptomrelated coping, and mood in patients following hematopoietic stem cell transplantation. Two models were analyzed with a within-person mediating role of coping and mood, respectively. Physical symptoms, coping (brooding, reflection, co-rumination, positive reframing, venting, acceptance, and active coping), and positive (PA) and negative affect (NA) were reported by 229 patients for 28 consecutive evenings after post-transplant hospital discharge. The mediating role of coping fluctuation was partially supported since a competitive model assuming coping reactivity was more reliable. Fluctuation in daily PA and NA mediated relationship of physical symptoms with brooding, co-rumination and venting. Daily changes in positive reframing, acceptance and reflection, partially mediated the association between changes in physical symptoms and mood. The study results indicate the usefulness of intervention addressed to the management of daily mood and stimulation of positive reframing and acceptance in post-HSCT patients.
\end{abstract}

Electronic supplementary material The online version of this article (https://doi.org/10.1007/s10865-018-9968-x) contains supplementary material, which is available to authorized users.

Aleksandra Kroemeke

akroemeke@swps.edu.pl

1 Department of Psychology, SWPS University of Social Sciences and Humanities, Chodakowska Street 19/31, 03-815 Warsaw, Poland

2 Maria Sklodowska-Curie-Oncology Center, Gliwice Branch, Gliwice, Poland
Keywords Emotions · Coping · Daily study · Hematopoietic stem cell transplantation - Mediation . Physical symptoms

\section{Introduction}

Hematopoietic stem cell transplantation (HSCT) is an effective therapy for various malignant and non-malignant diseases. However, therapy-related conditioning regimen causes many adverse effects. Post-HSCT complications are mainly related to various physical symptoms, such as poor appetite, taste change, gastric problems, rashes or fatigue. Previous studies suggested a higher prevalence of physical symptoms in post-HSCT patients 2 weeks (Sherman et al., 2009) or even 7 years post-transplant (Andrykowski et al., 2005; Bieri et al., 2008) compared to general population. More adverse symptoms, in turn, are related to worse adjustment of patients (Bevans et al., 2008; Kenzik et al., 2015; Nelson et al., 2014).

Emotional state after HSCT may be partially due to the manner in which physical symptoms are a source of burden and provide a functional limitation of patient daily living. Outside the context of HSCT, daily physical symptoms were related to higher negative affect (NA) and lower positive affect (PA) (Cho et al., 2013; Chui \& Diehl, 2016; Conner et al., 2006; Lay \& Hoppmann, 2014; Massey et al., 2011). Other studies suggested that an increased number of symptoms were related to more intense symptom-related coping behaviors (Cho et al., 2013; Conner et al., 2006; Golightly et al., 2015). Coping may constitute relevant protective or risk factors for changes in daily mood. According to Lazarus and Folkman (1984) stress-coping model, coping is one of the main variables responsible for patient adjustment. Coping refers to the "cognitive and 
behavioral efforts to manage specific external and/or internal demands that are appraised as taxing or exceeding the resources of the person" (Lazarus \& Folkman, 1984, p. 141). Coping is a complex, dynamic, and idiosyncratic process. It mediates the effect of causal antecedents (characteristics of the person and his/her context) on immediate and long-term stress outcomes (health and wellbeing). Thus, coping is viewed as a response to perceiving stress (e.g. somatic burden) and is directed at regulating stress outcomes (e.g. affect). For example, rumination, suppression, and avoidance coping were found to increase daily NA and decrease PA. On the other hand, reflection, reappraisal, acceptance, social sharing and problem-solving strategies enhanced daily PA (Brans et al., 2013; Cho et al., 2013; Dunkley et al., 2014; Massey et al., 2011; Roesch et al., 2009).

Symptom-related coping may mediate the relationship between daily physical symptoms and mood changes, based on the transactional stress-coping theory (Lazarus \& Folkman, 1984). Some studies have already investigated this issue (Barakat et al., 2007; Smorti et al., 2014), however, not in the context of everyday life or specific variability of individuals. Although Gruszczyńska and Knoll (2015) investigated lower-level mediating effect of meaning-focused coping in association with pain and PA, dynamic compounds between these variables were not tested (only the same-day associations were analyzed). In fact, the transactional stress model has still not been fully verified. In particular, less is known about the reciprocal dependencies between coping process variables and their changes over time (if and how changes in stress-related variables co-occur with one another). For example, Carver and Scheier (1994) indicated that coping process might, in fact, be rather reactive (i.e. emotions predict coping) than intentional, however, this has not been verified in a daily diary approach yet. The exception is the study by Müller et al. (2017) on the within-person mediating effect of PA and NA in the relationship between catastrophizing and fatigue. Both PA and NA mediated the effect of coping on the increase in fatigue, whereas only NA mediated the reverse relationship. Still, the above analyses were limited to a single symptom and a single coping strategy.

Therefore, the aim of this study was to determine the role of the fluctuation of the symptom-related coping strategies and mood (PA and NA) in relation to physical symptom fluctuations in daily life of patients following HSCT. Among the various coping strategies, brooding, reflection, positive reframing, acceptance, venting, co-rumination, and active coping were analyzed. Brooding refers to passive directing the attention inward, particularly in respect to negative feelings and symptoms (Treynor et al., 2003). Reflection involves a purposeful turning inward oriented at drawing constructive conclusions for the future, with neither a change in stressful setting perception nor emotional state (Treynor et al., 2003). In turn, positive reframing refers to reappraisal of a current situation to assign a positive meaning which changes the emotional response (Gross, 1998). Acceptance involves the adoption of stressful circumstances (Carver et al., 1989). Venting refers to focusing on a negative state with its simultaneous disclosure (Carver et al., 1989). Co-rumination includes an intense analysis and discussion of one's own problems and the accompanying negative emotions with other people (Rose, 2002). Active coping includes direct actions to solve the problem (Carver et al., 1989).

To address the dynamic relationship between variables, the association between parallel changes (from the prior day to the present day) in daily symptoms, symptom-related coping, and mood was tested. Based on the transactional stress model (Lazarus \& Folkman, 1984) and the above empirical evidence, it was expected that (1) an increase in physical symptoms would be related to an increase in NA and a decrease in PA, as well as (2) an increase in coping mechanisms, and (3) that the symptommood association would be mediated by concurrent changes in symptom-related coping strategies. The effect of reflection, positive reframing, acceptance, co-rumination, and active coping would be beneficial, whereas for brooding and venting the result would be detrimental.

Apart from investigating the dynamic relationship in the transactional stress-coping model and coping mediation hypothesis, this study also adds to the literature by investigating coping reactivity (Carver \& Scheier, 1994) in HSCT patients. For this purpose, the reverse mediation model was examined (from daily physical symptoms via daily affect to daily coping strategies). Understanding coping mechanisms (instrumental vs. reactive) will indicate the direction of psychological intervention in patients following HSCT. In addition, this study features a rare intensive longitudinal approach of 4 weeks of daily report of patients' fairly immediate recovery following HSCT.

\section{Methods}

\section{Procedure and participants}

The inclusion criteria for the study were the first HSCT and no history of other major disabling medical or psychiatric condition, and written informed consent. The recruitment occurred after elective hospital admission for HSCT. The daily assessment started from the first day of hospital discharge and lasted 28 consecutive days. All patients completed self-report web-based (13\%) or paper-and-pencil $(87 \%)$ diaries in the evening. They also received a short text message every evening as a reminder to fill in a diary 
and were called thrice during the 28-day period to address any difficulties and/or answer any questions (first call on Day 2 in the morning). The study protocol was approved by the University Ethics Committee (decision No. 24/2014). The participant flowchart is presented in Figure S1. The final sample comprised 229 patients after HSCT. Most participants were in a stable relationship, had at least a secondary education, were professionally inactive, and assessed their economic status as average (Table 1). The majority of the participants were patients with lymphomas, autologous HSCT, and high-intensity conditioning. Sample attrition analyses (using a binomial logistic regression) indicated that the diary study completers and non-completers did not differ in terms of demographic or clinical variables, except the type of transplant $(B=1.24, S E=$ $.30, p<.001)$. Allogeneic HSCT was associated with an increased likelihood of being non-completers.

\section{Measures}

\section{Daily physical symptoms}

The daily physical symptoms scale consisted of 21 symptoms (dyspnea, tightness in chest, dizziness, nausea, vomiting, diarrhea, constipation, skin rash, numbness/tingling, pain i.e. headache, backache, muscle soreness and other, dry/sore mouth and burning sensation in the mouth, altered/ loss of sense of taste, burning/dry eyes, fatigue, trouble concentrating, insomnia, appetite loss, cough/runny nose) based on EORTC QOL-C30 symptom scales (Sprangers et al., 1998), Larsen and Kasimatis (1991) daily physical symptom scale, and HSCT-related symptoms. The participants checked the symptoms they experienced during each day, responding to the instruction: "Today I have experienced the following symptoms (check all that apply)".

Table 1 Sample characteristics $(N=229)$

\begin{tabular}{|c|c|c|}
\hline Characteristics & $n(\%)$ & $M(S D)$, range \\
\hline \multicolumn{3}{|l|}{ Demographic } \\
\hline Male & $127(55.5)$ & \\
\hline Employment: yes & $82(35.8)$ & \\
\hline Marital status: married/partnership & $195(85.2)$ & \\
\hline \multicolumn{3}{|l|}{ Subjective economic status } \\
\hline Above average & $27(11.8)$ & \\
\hline Average & $183(79.9)$ & \\
\hline Below average & $19(8.3)$ & \\
\hline Age (years) & & $47.83(13.45), 19-68$ \\
\hline Education (years) & & $14.13(3.25), 6-28$ \\
\hline \multicolumn{3}{|l|}{ Clinical } \\
\hline \multicolumn{3}{|l|}{ Primary diagnosis } \\
\hline Leukemias and other myeloid neoplasms & $42(18.3)$ & \\
\hline Lymphomas & $105(45.9)$ & \\
\hline Multiple myeloma & $73(31.9)$ & \\
\hline Other cancer types (solid tumor, other) & $9(3.9)$ & \\
\hline \multicolumn{3}{|l|}{ Medical comorbidities } \\
\hline None & $114(48.1)$ & \\
\hline 1 & $66(27.8)$ & \\
\hline 2 & $31(13.1)$ & \\
\hline 3 or more & $18(11.0)$ & \\
\hline \multicolumn{3}{|l|}{ Type of transplant } \\
\hline Autologous (autoHSCT) & $168(73.4)$ & \\
\hline Allogeneic (alloHSCT) & $61(26.6)$ & \\
\hline Myeloablative conditioning & $219(95.6)$ & \\
\hline Time since diagnosis (months) & & 21.48 (24.83), 3-180 \\
\hline Medical comorbidities & & $.94(1.26), 0-7$ \\
\hline Days from HSCT to discharge & & $18.61(9.26), 10-91$ \\
\hline AutoHSCT recipients & & $14.45(3.50), 10-33$ \\
\hline AlloHSCT recipients & & 30.05 (10.47), 17-91 \\
\hline
\end{tabular}


Adding additional symptoms was optional for the study participants. The narrative responses were compared against the symptoms on the scale and the symptoms that differed from the scaled items were added as the 22 nd symptom (total daily score: $0-22$ ).

\section{Daily symptom-related coping strategies}

Seven kinds of daily symptom- and health-related coping strategies were analyzed, with two items per scale. Brooding and reflection were measured using Ruminative Response Scale (RRS) items (Treynor et al., 2003). Corumination was measured using Co-Rumination Questionnaire (CRQ) items (Davidson et al., 2014; Rose, 2002). Venting, positive reframing, acceptance, and active coping were measured with the abbreviated, situational version of COPE items (Brief COPE) (Carver, 1997). All statements referred to coping used on each particular day and were assessed on a 4-point scale from 1 (I haven't been doing this at all) to 4 (I've been doing this a lot). A higher result in each scale indicated greater coping efforts in a particular type (total daily score per scale: $2-8$ ).

\section{Daily PA and NA}

Mood fluctuations were measured using ten items from the Positive and Negative Affect Schedule (PANAS) (Watson et al., 1988). The study participants rated how they felt on a particular day, using a seven-point scale ranging from 1 (not at all) to 7 (very strongly). Higher scores indicated greater PA and NA, respectively (total daily score per scale: 5-35).

Within-person and between-person reliabilities (coefficient omega) are presented in Table 2. All indicators had acceptable reliability coefficients, considering the doubleitem nature of some indicators.

\section{Statistical analysis}

Multilevel structural equation modeling (MSEM) was conducted using Mplus statistical package ver. 8 (Preacher et al., 2011) to examine the within-person mediation (i.e. 1-1-1 mediation). MSEM is based on the general latent variable modeling framework, thus it is more flexible than the conventional multilevel approach (Preacher et al., 2011). Two models were tested: (1) analyzing the effect of changes in physical symptoms on affect trough changes in coping strategies in post-HSCT patients, and (2) examining the effect of changes in physical symptoms on coping through changes in mood fluctuations (reverse model relative to transactional stress model). Due to the fact that we were interested in the effects on the lower level only, the impact of between-person differences in the overall level was omitted (Bolger \& Laurenceau, 2013). Mplus code as provided by Bolger and Laurenceau (2013) was used. All variables were group-mean centered to analyze only their within-person part (time-varying fluctuation around the person's mean) (Bolger \& Laurenceau, 2013). The within-

Table 2 Descriptive statistics, intraclass correlation coefficients (ICCs), within-person and between-person reliabilities (coefficient omega, $\omega$ ), and within-person correlations

\begin{tabular}{|c|c|c|c|c|c|c|c|c|c|c|}
\hline & 1. & 2. & 3. & 4. & 5. & 6. & 7. & 8. & 9. & 10. \\
\hline $\begin{array}{l}\text { 1. Physical } \\
\text { symptoms }\end{array}$ & & $-.30 * * *$ & $.32 * * *$ & $.07 * * *$ & $.12 * * *$ & $.06 * * *$ & $.04 * *$ & $-.06 * * *$ & $-.04 * *$ & $-.03 *$ \\
\hline 2. Positive affect & & & $-.44 * * *$ & $-.12 * * *$ & $-.14 * * *$ & $.04 * *$ & .01 & $.20 * * *$ & $.23 * * *$ & $.11 * * *$ \\
\hline 3. Negative affect & & & & $.18 * * *$ & $.20 * * *$ & $-.05 * *$ & $.17 * * *$ & $-.04 * *$ & $-.09 * * *$ & -.02 \\
\hline 4. Brooding & & & & & $.62 * * *$ & $.21 * * *$ & $.26 * * *$ & $.17 * * *$ & $.03 * *$ & $.24 * * *$ \\
\hline 5. Reflection & & & & & & $.24 * * *$ & $.25^{* * *}$ & $.20 * * *$ & $.05 * * *$ & $.28 * * *$ \\
\hline 6. Co-rumination & & & & & & & $.22 * * *$ & $.29 * * *$ & $.13 * * *$ & $.19 * * *$ \\
\hline 7. Venting & & & & & & & & $.34 * * *$ & $.17 * * *$ & $.32 * * *$ \\
\hline $\begin{array}{l}\text { 8. Positive } \\
\text { Reframing }\end{array}$ & & & & & & & & & $.33 * * *$ & $.33 * * *$ \\
\hline 9. Acceptance & & & & & & & & & & $.28 * * *$ \\
\hline \multicolumn{11}{|l|}{ 10. Active Coping } \\
\hline Mean & 3.63 & 14.68 & 9.82 & 2.86 & 3.22 & 3.74 & 3.63 & 3.95 & 5.45 & 4.24 \\
\hline$S D$ & 2.83 & 4.72 & 3.59 & 1.34 & 1.46 & 1.88 & 1.36 & 1.73 & 1.61 & 1.66 \\
\hline $\mathrm{ICC}$ & .74 & .63 & .55 & .62 & .59 & .68 & .57 & .61 & .61 & .62 \\
\hline Within-level $\omega$ & & .94 & .90 & .96 & .90 & .98 & .55 & .95 & .63 & .93 \\
\hline Between-level $\omega$ & & .87 & .87 & .56 & .56 & .56 & .56 & .56 & .56 & .56 \\
\hline
\end{tabular}

$* p<.05 ; * *<.01 ; * * p<.001$ 
person change scores were calculated by subtracting today scores from yesterday scores $\left(\Delta\right.$ Variable $=$ Variable $_{i t}-$ Variable $\left._{i t-1}\right)$. Outcomes were tested separately; random intercepts and slopes were estimated. Mediators were tested separately to avoid multicollinearity. Time was centered on the middle time point and controlled in estimations. The maximum likelihood was used as an estimator.

\section{Results}

\section{Preliminary analyses}

The number of missing observations was $11 \%$ (across all days and participants). A total of 185 participants (81\%) completed at least 26 of the 28 daily diaries. The final analysis dataset consisted of 5889 daily reports from 229 participants. The missing pattern analysis indicated no significant associations between missing-record group membership and the analyzed variables except positive reframing intercept i.e. a higher initial level of positive reframing was observed in the missing-record group $(p=.036)$. Descriptive statistics, within-person correla- tions, and intraclass correlation coefficients of daily physical symptoms, symptom-related coping strategies, and affect are presented in Table 2.

\section{Within-subject mediation analyses: coping as a mediator}

Within-person change of physical symptoms was directly and indirectly related to parallel within-person change in PA fluctuation (Table 3). The specific indirect effects that were significant involved brooding, reflection, venting, positive reframing, and acceptance. The increase in physical symptoms was associated with a parallel increase in brooding, reflection, and venting, and a decrease in positive reframing and acceptance. In turn, coping change was related to a parallel decrease in PA. The indirect effects accounted for $4-9 \%$ of the overall average relationship between physical symptoms and PA fluctuation (Table S1).

For within-person change in NA fluctuation, similar results were obtained except positive reframing, which was not a significant mediator (Table 3). The increase in daily NA was related to a parallel increase in physical symptoms, as well as a symptom-related increase in brooding, reflection, and venting, and a decrease in acceptance.

Table 3 Lower-level mediation results (MSEM)

\begin{tabular}{|c|c|c|c|c|c|c|c|}
\hline \multirow[t]{2}{*}{ Predictor } & \multirow{2}{*}{$\begin{array}{l}\rightarrow \text { Mediator } \\
\rightarrow\end{array}$} & \multirow[t]{2}{*}{ Outcome } & \multicolumn{3}{|l|}{$B(S E)$} & \multicolumn{2}{|l|}{ Average effect $[95 \% \mathrm{CI}]$} \\
\hline & & & $a$ path & $b$ path & $c^{\prime}$ path & Total effect & Indirect effect \\
\hline \multirow{7}{*}{$\begin{array}{l}\Delta \text { Physical } \\
\text { Symptoms }\end{array}$} & $\Delta$ Brooding & \multirow{7}{*}{$\begin{array}{c}\Delta \text { Positive } \\
\text { Affect }\end{array}$} & $.04(.01)^{* *}$ & $-.21(.07)^{* *}$ & $-.50(.05)^{* * *}$ & $-.52[-.60 ;-.45]$ & $-.02[-.04 ;-.003]$ \\
\hline & $\Delta$ Reflection & & $.06(.02) * * *$ & $-.23(.06)^{* * *}$ & $-.47(.04)^{* * *}$ & $-.52[-.59 ;-.44]$ & $-.05[-.07 ;-.02]$ \\
\hline & $\begin{array}{l}\Delta \mathrm{Co}- \\
\quad \text { rumination }\end{array}$ & & $.02(.02)$ & $.11(.05)^{*}$ & $-.53(.05)^{* * *}$ & $-.53[-.60 ;-.45]$ & $.00[-.02 ; .02]$ \\
\hline & $\Delta$ Venting & & $.02(.02)$ & $-.11(.06)^{*}$ & $-.49(.04)^{* * *}$ & $-.52[-.60 ;-.45]$ & $-.04[-.05 ;-.02]$ \\
\hline & $\begin{array}{l}\Delta \text { Positive } \\
\text { Reframing }\end{array}$ & & $-.04(.02)^{* *}$ & $.29(.05) * * *$ & $-.50(.05)^{* * *}$ & $-.53[-.60 ;-.45]$ & $-.02[-.04 ;-.01]$ \\
\hline & $\Delta$ Acceptance & & $-.04(.02)^{*}$ & $.28(.05)^{* * *}$ & $-.48(.04)^{* * *}$ & $-.52[-.59 ;-.45]$ & $-.04[-.06 ;-.02]$ \\
\hline & $\begin{array}{l}\Delta \text { Active } \\
\text { Coping }\end{array}$ & & $.02(.02)$ & $.09(.05)$ & $-.51(.05)^{* * *}$ & $-.52[-.60 ;-.45]$ & $-.01[-.03 ; .01]$ \\
\hline \multirow{7}{*}{$\begin{array}{l}\Delta \text { Physical } \\
\text { Symptoms }\end{array}$} & $\Delta$ Brooding & \multirow{7}{*}{$\begin{array}{c}\Delta \text { Negative } \\
\text { Affect }\end{array}$} & $.04(.01)^{* *}$ & $.34(.06)^{* * *}$ & $.36(.04)^{* * *}$ & $.39[.32 ; .46]$ & $.02[.004 ; .05]$ \\
\hline & $\Delta$ Reflection & & $.06(.02)^{* * *}$ & $.34(.05)^{* * *}$ & $.35(.04)^{* * *}$ & $.39[.32 ; .46]$ & $.04[.02 ; .06]$ \\
\hline & $\begin{array}{l}\Delta \mathrm{Co}- \\
\quad \text { rumination }\end{array}$ & & $.02(.02)$ & $-.004(.04)$ & $.38(.04)^{* * *}$ & $.38[.31 ; .45]$ & $.001[-.01 ; .02]$ \\
\hline & $\Delta$ Venting & & $.02(.02)$ & $.29(.05)^{* * *}$ & $.37(.04)^{* * *}$ & $.39[.32 ; .46]$ & $.02[.002 ; .04]$ \\
\hline & $\begin{array}{l}\Delta \text { Positive } \\
\quad \text { Reframing }\end{array}$ & & $-.05(.02)^{* *}$ & $-.08(.05)$ & $.38(.04)^{* * *}$ & $.39[.32 ; .46]$ & $.01[-.01 ; .03]$ \\
\hline & $\Delta$ Acceptance & & $-.04(.02)^{\wedge}$ & $-.18(.05)^{* * *}$ & $.35(.04)^{* * *}$ & $.38[.32 ; .46]$ & $.03[.02 ; .05]$ \\
\hline & $\begin{array}{l}\Delta \text { Active } \\
\text { Coping }\end{array}$ & & $.02(.02)$ & $-.02(.04)$ & $.38(.04)^{* * *}$ & $.39[.32 ; .46]$ & $.01[-.01 ; .02]$ \\
\hline
\end{tabular}

$\Delta$, change from the prior day $(t-1)$ to the present day $(t) ; a$ path, the predictor-to-mediator relationship; $b$ path, the mediator-to-outcome relationship; $c^{\prime}$ path, the predictor-to-outcome direct effect

${ }^{\wedge} p=.051 ; * p<.05 ; * * p<.01 ; * * * p<.001$ 
Indirect effects accounted for $6-10 \%$ of the overall average $\Delta$ symptoms $-\Delta$ NA relationship (Table S1).

In order to rule out confounds, the mediation models were repeated with covariates (i.e. age, sex, education, employment, primary diagnosis, type of transplant, time since diagnosis, days from HSCT to discharge, and comorbidities). None of the covariates were related to mediators or outcomes. No changes in the results of lowerlevel mediation were observed.

\section{Reverse-mediation model analyses: affect as a mediator}

Reversal of the relationship between coping and mood revealed a better model fit for brooding, co-rumination, venting, and partially for reflection, acceptance and active coping (Table 4) and higher percent mediation effects (24-66\%; Table S2). Increase in physical symptoms was related to a parallel increase in NA and a decrease in PA, which, in turn, was associated with an increase in brooding and reflection, and a decrease in acceptance (Table 5). PA fluctuations mediated the dynamic relationship of physical symptoms with positive reframing and co-rumination, being decreased with higher symptoms and thus reducing the above coping. The effect on venting was mediated by NA fluctuations. For co-rumination and venting, indirect effects suppressed direct effects. As previously, covariates did not substantially change the mediation results.

\section{Discussion}

The study aimed at examining the mediating effect of symptom-related coping strategies in the relationship between daily parallel changes in physical symptoms and affect (positive and negative). Also, we investigated the reverse model with the mediating effect of daily mood fluctuations in symptom-coping relationship in patients following HSCT. To the best of our knowledge, this study is one of the first that explores the dynamic, reciprocal dependencies in the transactional stress-coping model at the within-person level. The hypothesis of the mediating role of daily coping, resulting from the transactional theory assumptions, was only partially supported as the competitive model assuming coping reactivity was more reliable.

In line with the transactional stress-coping model, daily changes in positive reframing, acceptance, and reflection partially mediated the association between changes in daily physical symptoms and mood fluctuation. While positive reframing and reflection predicted PA fluctuations, acceptance predicted NA changes. The effect of positive reframing and acceptance was beneficial, thus supporting previous findings (Brans et al., 2013; Chiros \& O'Brien, 2011; Cho et al., 2013; Dunkley et al., 2014; Roesch et al., 2009). Their increase was related to an increase in PA and a decrease in NA, respectively. The results of this study suggest these adaptive coping strategies may participate in the association between functional limitations associated with physical symptoms and psychological functioning.

Table 4 Model fit indices of within-person multilevel meditation model based on transactional theory (symptoms-coping-affect) and reverse model (symptoms-affect-coping)

\begin{tabular}{|c|c|c|c|c|c|c|c|c|}
\hline \multirow[t]{2}{*}{ Mediator/outcome } & \multicolumn{4}{|c|}{ Model: $\Delta$ symptoms $-\Delta$ coping $-\Delta$ affect } & \multicolumn{4}{|c|}{ Model: $\Delta$ symptoms $-\Delta$ affect $-\Delta$ coping } \\
\hline & Log likelihood & AIC & $\mathrm{BIC}$ & SSABIC & $-2 \log$ likelihood & AIC & $\mathrm{BIC}$ & SSABIC \\
\hline Brooding, NA & $-20,256.24$ & $40,538.48$ & $40,624.73$ & $40,583.43$ & $-20,245.40$ & $40,516.80$ & $40,603.06$ & $40,561.75$ \\
\hline Brooding, PA & $-21,193.23$ & $42,412.45$ & $42,498.72$ & $42,457.41$ & $-21,173.09$ & $42,372.18$ & $42,458.44$ & $42,417.13$ \\
\hline Reflection, NA & $-21,114.02$ & $42,254.04$ & $42,340.30$ & $42,298.99$ & $-21,113.11$ & $42,252.22$ & $42,338.48$ & $42,297.17$ \\
\hline Reflection, PA & $-22,033.53$ & $44,093.06$ & $44,179.32$ & $44,138.01$ & $-22,036.25$ & $44,098.50$ & $44,184.77$ & $44,143.46$ \\
\hline Co-rumination, NA & $-21,898.94$ & $43,823.87$ & $43,910.12$ & $43,868.81$ & $-21,896.20$ & $43,818.39$ & $43,904.64$ & $43,863.33$ \\
\hline Co-rumination, PA & $-22,781.37$ & $45,588.73$ & $45,674.99$ & $45,633.68$ & $-22,770.58$ & $45,567.16$ & $45,653.42$ & $45,612.11$ \\
\hline Venting, NA & $-20,960.28$ & $41,946.55$ & $42,032.81$ & $41,991.50$ & $-20,959.85$ & $41,945.69$ & $42,031.95$ & $41,990.64$ \\
\hline Venting, PA & $-21,912.42$ & $43,850.84$ & $43,937.11$ & $43,895.80$ & $-21,909.87$ & $43,845.73$ & $43,932.00$ & $43,890.69$ \\
\hline Positive Reframing, NA & $-21,672.49$ & $43,370.97$ & $43,457.21$ & $43,415.90$ & $-21,675.24$ & $43,376.47$ & $43,462.72$ & $43,421.41$ \\
\hline Positive Reframing, PA & $-22,554.58$ & $45,135.16$ & $45,221.42$ & $45,180.11$ & $-22,560.74$ & $45,147.49$ & $45,233.74$ & $45,192.43$ \\
\hline Acceptance, NA & $-21,164.94$ & $42,355.88$ & $42,442.13$ & $42,400.82$ & $-21,172.94$ & $42,371.87$ & $42,458.12$ & $42,416.81$ \\
\hline Acceptance, PA & $-22,065.96$ & $44,157.93$ & $44,244.19$ & $44,202.88$ & $-22,069.12$ & $44,164.24$ & $44,250.51$ & $44,209.120$ \\
\hline Active Coping, NA & $-21,422.51$ & $42,871.02$ & $42,957.27$ & $42,915.96$ & $-21,418.71$ & $42,863.42$ & $42,949.66$ & $42,908.35$ \\
\hline Active Coping, PA & $-22,278.77$ & $44,583.54$ & $44,669.81$ & $44,628.50$ & $-22,272.40$ & $44,570.79$ & $44,657.06$ & $44,615.75$ \\
\hline
\end{tabular}

The model with the lower AIC, BIC and SSABIC values indicated better fit (better models in italics)

$N A$ negative affect, $P A$ positive affect, $A I C$ the Akaike Information Criterion, BIC the Bayesian Information Criterion, SSABIC the Sample-Size Adjusted Bayesian Information Criterion 
Table 5 Lower-level reverse model mediation results (MSEM)

\begin{tabular}{|c|c|c|c|c|c|c|}
\hline \multirow[t]{2}{*}{ Predictor $\rightarrow$ Outcome } & \multirow[t]{2}{*}{ Mediator } & \multicolumn{3}{|l|}{$B(S E)$} & \multicolumn{2}{|c|}{ Average effect $[95 \% \mathrm{CI}]$} \\
\hline & & $a$ path & $b$ path & $c^{\prime}$ path & Total effect & Indirect effect \\
\hline \multirow[t]{2}{*}{$\Delta \mathrm{PS} \rightarrow \Delta$ Brooding } & $\Delta \mathrm{NA}$ & $.39(.04)^{* * *}$ & $.04(.01)^{* * *}$ & $.02(.01)$ & $.04[.02 ; .07]$ & $.02[.01 ; .03]$ \\
\hline & $\Delta \mathrm{PA}$ & $-.53(.05)^{* * *}$ & $-.02(.01)^{* *}$ & $.03(.01)^{*}$ & $.04[.02 ; .07]$ & $.02[.01 ; .03]$ \\
\hline \multirow[t]{2}{*}{$\Delta \mathrm{PS} \rightarrow \Delta$ Reflection } & $\Delta \mathrm{NA}$ & $.38(.04)^{* * *}$ & $.06(.01)^{* * *}$ & $.03(.02)^{*}$ & $.06[.04 ; .09]$ & $.03[.02 ; .04]$ \\
\hline & $\Delta \mathrm{PA}$ & $-.53(.05)^{* * *}$ & $-.03(.01)^{* * *}$ & $.04(.02)^{*}$ & $.06[.03 ; .08]$ & $.02[.01 ; .03]$ \\
\hline \multirow[t]{2}{*}{$\Delta \mathrm{PS} \rightarrow \Delta$ Co-rumination } & $\Delta \mathrm{NA}$ & $.39(.04)^{* * *}$ & $-.01(.01)$ & $.03(.02)$ & $.02[-.01 ; .05]$ & $-.01[-.02 ; .004]$ \\
\hline & $\Delta \mathrm{PA}$ & $-.54(.05)^{* * *}$ & $.02(.01)^{*}$ & $.04(.02)^{\wedge}$ & $.02[-.01 ; .05]$ & $-.02[-.03 ;-.004]$ \\
\hline \multirow[t]{2}{*}{$\Delta \mathrm{PS} \rightarrow \Delta$ Venting } & $\Delta \mathrm{NA}$ & $.39(.04)^{* * *}$ & $.05(.01)^{* * *}$ & $-.01(.01)$ & $.02[-.01 ; .04]$ & $.02[.01 ; .03]$ \\
\hline & $\Delta \mathrm{PA}$ & $-.53(.05)^{* * *}$ & $-.01(.01)$ & $.01(.01)$ & $.02[-.004 ; .04]$ & $.01[-.002 ; .02]$ \\
\hline \multirow[t]{2}{*}{$\Delta \mathrm{PS} \rightarrow \Delta$ Positive Reframing } & $\Delta \mathrm{NA}$ & $.39(.05)^{* * *}$ & $-.02(.01)$ & $-.03(.02)$ & $-.04[-.07 ;-.02]$ & $-.01[-.02 ; .00]$ \\
\hline & $\Delta \mathrm{PA}$ & $-.53(.05)^{* * *}$ & $.04(.01)^{* * *}$ & $-.02(.02)$ & $-.04[-.07 ;-.01]$ & $-.02[-.03 ;-.01]$ \\
\hline \multirow[t]{2}{*}{$\Delta \mathrm{PS} \rightarrow \Delta$ Acceptance } & $\Delta \mathrm{NA}$ & $.38(.04) * * *$ & $-.03(.01)^{* *}$ & $-.02(.02)$ & $-.03[-.06 ;-.01]$ & $-.02[-.03 ;-.01]$ \\
\hline & $\Delta \mathrm{PA}$ & $-.53(.05)^{* *}$ & $.04(.01)^{* * *}$ & $-.01(.02)$ & $-.03[-.06 ;-.01]$ & $-.02[-.03 ;-.01]$ \\
\hline \multirow[t]{2}{*}{$\Delta \mathrm{PS} \rightarrow \Delta$ Active Coping } & $\Delta \mathrm{NA}$ & $.39(.04) * * *$ & $-.001(.01)$ & $.02(.02)$ & $.02[-.001 ; .05]$ & $.004[-.001 ; .01]$ \\
\hline & $\Delta \mathrm{PA}$ & $-.54(.05)^{* * *}$ & $.02(.01)^{* *}$ & $.03(.02)$ & $.02[-.01 ; .05]$ & $-.01[-.02 ; .002]$ \\
\hline
\end{tabular}

$P S$ physical symptoms, $N A$ negative affect, $P A$ positive affect, $\Delta$ change from the prior day $(t-1)$ to the present day $(t), a$ path the predictor-tomediator relationship, $b$ path the mediator-to-outcome relationship, $c^{\prime}$ path the predictor-to-outcome direct effect

${ }^{\wedge} p=.051 ; * p<.05 ; * * p<.01 ; * * * p<.001$

Reflection demonstrated a detrimental effect as its increase co-occurred with the decline in daily PA. This association may be surprising because reflection is defined as a positive form of rumination (Treynor et al., 2003) and was found to enhance PA or undermine NA in intensive longitudinal (Brans et al., 2013) and traditional longitudinal studies (Burwell \& Shirk, 2007). Other traditional studies, however, indicated that reflection may trigger brooding (Elliott $\&$ Coker, 2008) and its adaptive function may depend on the surrounding coping strategies (Marroquín et al., 2010). Further studies at the within-person level are needed in this area.

The percent of mediation effects by daily coping was higher for NA, but generally lower compared to the mediation effect of daily mood fluctuation. Daily changes in symptom-related coping were rather reactive than intentional, i.e. daily mood changes mediated the dynamic relationship of physical symptoms with coping, especially with brooding, co-rumination, venting, and partly with acceptance and reflection. Of note, the effect via NA fluctuation on brooding and venting, and the effect via PA fluctuation on acceptance demonstrated full mediation. The findings are in contradiction to the assumptions as to the prediction of the coping and coping outcomes in the transactional stress-coping model, but they are consistent with the inconclusive data on the causality in the relationship between coping and affect (Carver \& Scheier, 1994; Müller et al., 2017). Simultaneously, our findings confirm the assumption of processuality and complex dependencies in the coping process. They also broaden our knowledge about dynamic relationships in the transactional stress-coping model. The results of this study highlight daily mood as an integral component of daily physical symptom experience that can predict, in turn, symptomrelated coping. This study provides valuable insights into the mechanism of the ways individuals cope with their daily symptoms, though, the study results may be contextspecific. Thus, future studies are needed to verify whether the observed mechanism can be generalized to a broader context of daily coping, not only to disease conditions.

Of note, daily social sharing (co-rumination) occurred under the condition of positive mood fluctuation only. Also, a relationship between daily acceptance and reflection with daily mood was interesting. Acceptance predicted NA fluctuations and was predicted by PA fluctuations, while the association of daily reflection was opposite. This result may support a distinct function and independence of PA from NA fluctuations in daily life (Fredrickson, 2001), as well as more complex and reciprocal dependencies between stress model variables.

The results of this study are consistent with previous research highlighting the association between daily physical symptoms and mood (Cho et al., 2013; Chui \& Diehl, 2016; Conner et al., 2006; Lay \& Hoppmann, 2014; Massey et al., 2011), indicating not only the same-day association, but also the association between both symptoms and mood change. However, due to the analysis of parallel changes, it is possible that the change in daily physical 
symptoms was the result of an increased daily NA and a decreased daily PA, as suggested by other researchers (Larsen \& Kasimatis, 1991). Further studies are needed in this area as the above study was conducted in healthy participants and therefore may not reflect the daily physical symptom-mood dependencies in disease circumstances.

Contrary to the expectations and previous findings (Conner et al., 2006; Golightly et al., 2015), more daily symptoms were not related to more daily coping, regardless of the content. Increased daily symptoms were rather related to an increase in the so-called maladaptive daily strategies (brooding and venting) and to a decrease in those defined as adaptive (positive reframing, acceptance, corumination). Symptom-affect interdependence and the mediating role of the daily affect in our study may explain these findings. In addition, daily active coping, the only problem-solving strategy, was not significantly related to both daily physical symptoms or NA. Active coping is probably triggered and maintained in a controllable situation (Lazarus \& Folkman, 1984) while post-HSCT settings are rather seen as uncontrollable.

\section{Study limitations}

The findings of this study may be limited given the heterogeneity of the sample, reliance on self-report indices, the analysis of parallel changes, and separate models for each strategy and affect. However, they may guide potential future avenues for research. The sample comprised patients with various primary diagnoses (with a predominance of lymphomas) and disproportions in the type of transplant (autologous vs. allogeneic, with a predominance of the former). However, most patients underwent myeloablative (high-intensity) conditioning, which largely determines post-HSCT adverse symptoms. Still, larger groups of patients with allogeneic transplant should be enrolled in further studies. Moreover, the data were selfreported, which could bias the study results. Furthermore, we tested the parallel changes in daily symptoms, affect, and coping. Therefore, we were not able to draw conclusions about the cause-and-effect relationships between variable changes. Future studies should investigate the causal relations, that is, the effect of prior within-person change $(t-1)$ in one variable on a subsequent change $(t+1)$ in this or another variable and potential mediators. Apart from the reverse association between affect and coping, the relationship between physical symptoms and affect could be reverse (as already mentioned). Finally, the separated models were examined. However, people employ multiple coping strategies simultaneously and experience both PA and NA fluctuations daily. Unfortunately, more complex models in our analyses did not reach convergence. Thus, further studies are required in this regard to under- stand everyday coping with illness. Also, future studies could explore additional covariates such as baseline psychological well-being or daily stress level, which could affect the daily physical symptoms and mood changes. ${ }^{1}$

\section{Clinical implications}

Next to important theoretical implications, i.e. the verification of dynamic and reciprocal dependencies resulting from the transactional model of stress in everyday life, the findings have also clinical implications. Specifically, improving the functional aspect of the quality of life of patients after HSCT (i.e. physical symptom intervention) should rather target patient daily mood (PA and NA) than symptom-related coping. In other words, modification of the existing coping mechanism (particularly brooding, venting, and co-rumination) may be less effective than interventions improving daily affect. For example, the mindfulness-based interventions (e.g. information about body-mind relationship or breath- and body sensation-focused meditation) may be particularly useful. Previous daily diary intervention study (Davis et al., 2015) and a recent meta-analysis of randomized controlled trials (Gotink et al., 2015) confirmed the effectiveness of these tools in the reduction of both negative states and adverse physical symptoms in chronic condition. On the other hand, intervention focused on positive reframing and acceptance of the present somatic condition may be a part of the goal of mitigating a negative effect of physical symptoms on mood.

Funding The study was supported by the National Science Centre, Poland, Grant No. 2013/10/E/HS6/00189, to A.K.

\section{Compliance with ethical standards}

Conflict of interest Aleksandra Kroemeke, Zuzanna Kwissa-Gajewska and Małgorzata Sobczyk-Kruszelnicka declare that they have no conflict of interest.

Human and animal rights and Informed consent All procedures performed in studies involving human participants were in accordance with the ethical standards of the institutional research committee and with the 1964 Helsinki declaration and its later amendments or comparable ethical standards. Informed consent was obtained from all individual participants included in the study.

Open Access This article is distributed under the terms of the Creative Commons Attribution 4.0 International License (http:// creativecommons.org/licenses/by/4.0/), which permits unrestricted use, distribution, and reproduction in any medium, provided you give

\footnotetext{
${ }^{1}$ We tested all mediation models with baseline depressive symptoms (before HSCT) and daily stress level as covariates. However, the inclusion of these variables did not alter study findings.
} 
appropriate credit to the original author(s) and the source, provide a link to the Creative Commons license, and indicate if changes were made.

\section{References}

Andrykowski, M. A., Bishop, M. M., Hahn, E. A., Cella, D. F., Beaumont, J. L., Brady, M. J., et al. (2005). Long-term healthrelated quality of life, growth, and spiritual well-being after hematopoietic stem-cell transplantation. Journal of Clinical Oncology, 23, 599-608. https://doi.org/10.1200/JCO.2005.03. 189

Barakat, L. P., Schwartz, L. A., Simon, K., \& Radcliffe, J. (2007). Negative thinking as a coping strategy mediator of pain and internalizing symptoms in adolescents with sickle cell disease. Journal of Behavioral Medicine, 30, 199-208. https://doi.org/10. 1007/s10865-007-9103-x

Bevans, M. F., Mitchell, S. A., \& Marden, S. (2008). The symptom experience in the first 100 days following allogeneic hematopoietic stem cell transplantation (HSCT). Supportive Care in Cancer, 16, 1243-1254. https://doi.org/10.1007/s00520-0080420-6

Bieri, S., Roosnek, E., Helg, C., Verholen, F., Robert, D., Chapuis, B., et al. (2008). Quality of life and social integration after allogeneic hematopoietic SCT. Bone Marrow Transplantation, 42, 819-827. https://doi.org/10.1038/bmt.2008.253

Bolger, N., \& Laurenceau, J.-P. (2013). Intensive longitudinal methods: An introduction to diary and experience sampling research. New York: Guilford Press.

Brans, K., Koval, P., Verduyn, P., Lim, Y. L., \& Kuppens, P. (2013). The regulation of negative and positive affect in daily life. Emotion, 13, 926-939. https://doi.org/10.1037/a0032400

Burwell, R. A., \& Shirk, S. R. (2007). Subtypes of rumination in adolescence: Associations between brooding, reflection, depressive symptoms, and coping. Journal of Clinical Child \& Adolescent Psychology, 36, 56-65. https://doi.org/10.1080/ 15374410709336568

Carver, C. S. (1997). You want to measure coping but your protocol's too long: Consider the brief COPE. International Journal of Behavioral Medicine, 4, 92-100. https://doi.org/10.1207/ s15327558ijbm0401_6

Carver, C. S., \& Scheier, M. F. (1994). Situational coping and coping dispositions in a stressful transaction. Journal of Personality and Social Psychology, 66, 184-195.

Carver, C. S., Scheier, M. F., \& Weintraub, J. K. (1989). Assessing coping strategies: A theoretically based approach. Journal of Personality and Social Psychology, 56, 267-283.

Chiros, C., \& O'Brien, W. H. (2011). Acceptance, appraisals, and coping in relation to migraine headache: An evaluation of interrelationships using daily diary methods. Journal of Behavioral Medicine, 34, 307-320. https://doi.org/10.1007/s10865011-9313-0

Cho, S., McCracken, L. M., Heiby, E. M., Moon, D.-E., \& Lee, J.-H. (2013). Pain acceptance-based coping in complex regional pain syndrome Type I: Daily relations with pain intensity, activity, and mood. Journal of Behavioral Medicine, 36, 531-538. https:// doi.org/10.1007/s10865-012-9448-7

Chui, H., \& Diehl, M. (2016). Age differences in the effects of selfesteem. The link between physical symptoms and daily affect. GeroPsych, 29, 189-200. https://doi.org/10.1024/1662-9647/ a000157

Conner, T. S., Tennen, H., Zautra, A. J., Affleck, G., Armeli, S., \& Fifield, J. (2006). Coping with rheumatoid arthritis pain in daily life: Within-person analyses reveal hidden vulnerability for the formerly depressed. Pain, 126, 198-209. https://doi.org/10.1016/ j.pain.2006.06.033

Davidson, C. L., Grant, D. M., Byrd-Craven, J., Mills, A. C., Judah, M. R., \& Lechner, W. V. (2014). Psychometric properties of the Co-Rumination Questionnaire. Personality and Individual Differences, 70, 171-175. https://doi.org/10.1016/j.paid.2014.07. 002

Davis, M. C., Zautra, A. J., Wolf, L. D., Tennen, H., \& Yeung, E. W. (2015). Mindfulness and cognitive-behavioral interventions for chronic pain: Differential effects on daily pain reactivity and stress reactivity. Journal of Consulting and Clinical Psychology, 83, 24-35. https://doi.org/10.1037/a0038200

Dunkley, D. M., Ma, D., Lee, I. A., Preacher, K. J., \& Zuroff, D. C. (2014). Advancing complex explanatory conceptualizations of daily negative and positive affect: Trigger and maintenance coping action patterns. Journal of Counseling Psychology, 61, 93-109. https://doi.org/10.1037/a0034673

Elliott, I., \& Coker, S. (2008). Independent self-construal, selfreflection, and self-rumination: A path model for predicting happiness. Australian Journal of Psychology, 60, 127-134. https://doi.org/10.1080/00049530701447368

Fredrickson, B. L. (2001). The role of positive emotions in positive psychology. The American Psychologist, 56, 218-226.

Golightly, Y. M., Allen, K. D., Stechuchak, K. M., Coffman, C. J., \& Keefe, F. J. (2015). Associations of coping strategies with diary based pain variables among Caucasian and African American patients with osteoarthritis. International Journal of Behavioral Medicine, 22, 101-108. https://doi.org/10.1007/s12529-0139365-3

Gotink, R. A., Chu, P., Busschbach, J. J. V., Benson, H., Fricchione, G. L., \& Hunink, M. G. M. (2015). Standardised mindfulnessbased interventions in healthcare: An overview of systematic reviews and meta-analyses of RCTs. PLOS ONE, 10, e0124344. https://doi.org/10.1371/journal.pone.0124344

Gross, J. J. (1998). Antecedent- and response-focused emotion regulation: Divergent consequences for experience, expression, and physiology. Journal of Personality and Social Psychology, 74, 224-237.

Gruszczyńska, E., \& Knoll, N. (2015). Meaning-focused coping, pain, and affect: A diary study of hospitalized women with rheumatoid arthritis. Quality of Life Research, 24, 2873-2883. https://doi. org/10.1007/s11136-015-1031-6

Kenzik, K., Huang, I.-C., Rizzo, J. D., Shenkman, E., \& Wingard, J. (2015). Relationships among symptoms, psychosocial factors, and health-related quality of life in hematopoietic stem cell transplant survivors. Supportive Care in Cancer, 23, 797-807. https://doi.org/10.1007/s00520-014-2420-z

Larsen, R. J., \& Kasimatis, M. (1991). Day-to-day physical symptoms: Individual differences in the occurrence, duration, and emotional concomitants of minor daily illnesses. Journal of Personality, 59, 387-423.

Lay, J. C., \& Hoppmann, C. A. (2014). Spousal neuroticism moderates everyday problem-wellbeing associations in older couples. Health Psychology, 33, 803-812. https://doi.org/10. 1037/hea0000042

Lazarus, R. S., \& Folkman, S. (1984). Stress, appraisal, and coping. New York: Springer.

Marroquín, B. M., Fontes, M., Scilletta, A., \& Miranda, R. (2010). Ruminative subtypes and coping responses: Active and passive pathways to depressive symptoms. Cognition and Emotion, 24, 1446-1455. https://doi.org/10.1080/02699930903510212

Massey, E. K., Garnefski, N., Gebhardt, W. A., \& van der Leeden, R. (2011). A daily diary study on the independent and interactive effects of headache and self-regulatory factors on daily affect among adolescents. British Journal of Health Psychology, 16, 288-299. https://doi.org/10.1348/135910710X500828 
Müller, F., Stephenson, E., DeLongis, A., Smink, A., Van Ginkel, R. J., Tuinman, M. A., et al. (2017). The reciprocal relationship between daily fatigue and catastrophizing following cancer treatment: Affect and physical activity as potential mediators. Psycho-Oncology. https://doi.org/10.1002/pon.4574

Nelson, A. M., Coe, C. L., Juckett, M. B., Rumble, M. E., Rathouz, P. J., Hematti, P., et al. (2014). Sleep quality following hematopoietic stem cell transplantation: Longitudinal trajectories and biobehavioral correlates. Bone Marrow Transplantation, 49, 1405-1411. https://doi.org/10.1038/bmt.2014.179

Preacher, K. J., Zhang, Z., \& Zyphu, M. J. (2011). Alternative methods for assessing mediation in multilevel data: The advantages of multilevel sem. Structural Equation Modeling, 18, 161-182. https://doi.org/10.1080/10705511.2011.557329

Roesch, S. C., Vaughn, A. A., Aldridge, A. A., \& Villodas, F. (2009). Daily diaries and minority adolescents: Random coefficient regression modeling of attributional style, coping, and affect. International Journal of Psychology, 44, 393-400. https://doi. org/10.1080/00207590802644758

Rose, A. J. (2002). Co-rumination in the friendships of girls and boys. Child Development, 73, 1830-1843. https://doi.org/10.1111/ 1467-8624.00509

Sherman, A. C., Simonton, S., Latif, U., Plante, T. G., \& Anaissie, E. J. (2009). Changes in quality-of-life and psychosocial adjustment among multiple myeloma patients treated with high-dose melphalan and autologous stem cell transplantation. Biology of Blood and Marrow Transplantation, 15, 12-20. https://doi.org/ 10.1016/j.bbmt.2008.09.023

Smorti, M., Cappelli, F., Guarnieri, S., Bergesio, F., \& Perfetto, F. (2014). Depression and cardiac symptoms among AL amyloidosis patients: The mediating role of coping strategies. Psychology, Health \& Medicine, 19, 263-272. https://doi.org/10.1080/ 13548506.2013.802357

Sprangers, M. A., Cull, A., Groenvold, M., Bjordal, K., Blazeby, J., \& Aaronson, N. K. (1998). The European Organization for Research and Treatment of Cancer approach to developing questionnaire modules: An update and overview. EORTC Quality of Life Study Group. Quality of Life Research, 7, 291-300.

Treynor, W., Gonzalez, R., \& Nolen-Hoeksema, S. (2003). Rumination reconsidered: A psychometric analysis. Cognitive Therapy and Research, 27, 247-259. https://doi.org/10.1023/A: 1023910315561

Watson, D., Clark, L. A., \& Tellegen, A. (1988). Development and validation of brief measures of positive and negative affect: The PANAS scales. Journal of Personality and Social Psychology, 54, 1063-1070. 